\title{
Internationale polnisch-kroatische Konferenz: „Wpływ papieża Polaka, św. Jana Pawła II na społeczność chorwacką" (Der Einfluss des polnischen Papstes, des hl. Johannes Paul Il., auf die kroatische Gesellschaft)
}

Am 9. November 2017 fand in der Aula der Bibliothek der Päpstlichen Universität Johannes Paul II. in Krakau (UPJPII) unter der gemeinsamen Schirmherrschaft der kroatischen Präsidentin Kolinda Grabar-Kitarović und des polnischen Präsidenten Andrzej Duda die internationale polnisch-kroatische Konferenz unter der folgenden Überschrift statt: „Wpływ papieża Polaka, św. Jana Pawła II na społeczność chorwacką" (Der Einfluss des polnischen Papstes, des hl. Johannes Paul II., auf die kroatische Gesellschaft). Der Einladung in das Ehrenkomitee der Konferenz folgten: S. Em. Kardinal Josip Bozanić, S. Em. kardinal Stanisław Dziwisz, S. Exz. Erzbischof von Split-Makarska Marin Barišić, S. Exz. Erzbischof Marek Jędraszewski, Metropolit in Krakau. Die Konferenz war von Herrn Paweł Włodarczyk, dem Ehrenkonsul der Republik Kroatien, sowie von H. H. Prof. Dr. habil. Józef Stala, dem Prorektor der Päpstlichen Universität Johannes Paul II. in Krakau, organisiert worden. Dabei arbeiteten sie eng mit der Katholischen Universität in Zagreb und der Universität in Split zusammen. Die mediale Berichterstattung über die Konferenz übernahmen TVP1, Radio Polen, Gość niedzielny (polnische Zeitschrift) und Slobodna Dalmacija (kroatische Zeitung).

Im Jahr 2018 sind es genau 20 Jahre her, dass der polnische Papst Johannes Paul II. in Kroatien war. Der Hauptgrund für diese Reise waren die 
Seligsprechung von Kardinal Alojsij Stepinać sowie die Teilnahme an der 1700-Jahr-Feier der Stadt Split. Diese Pilgerfahrt Johannes Pauls II. im Jahr 1998 war der erste offizielle Besuch eines Staatsoberhaupts und beendete die Isolierung Kroatiens auf internationaler Ebene. Daher entstand die Idee, die internationale polnisch-kroatische Sonderkonferenz: „Wpływ papieża Polaka, św. Jana Pawła II na społeczność chorwacką” - „Zemljo Hrvatska Bog te blagoslovio", mit dem Ziel zu organisieren, im Gedenken daran diese beiden Völker, das kroatische und das polnische, die der Papst so geliebt hat, einander weiter anzunähern. Die Gesamtkonferenz sollte sich in zwei Teile gliedern: Der erste Teil „Papież Jan Paweł II w życiu mieszkańców Chorwacji” (Papst Johannes Paul II. im Leben der Einwohner Kroatiens) fand am 9. Oktober 2017 an der UPJPII in Krakau statt, während der zweite Teil „Udział papieża Jana Pawła II w odzyskaniu niepodległości państwa chorwackiego" (Der Beitrag von Papst Johannes Paul II. zur Erlangung der Unabhängigkeit des kroatischen Staates) für den 5. Mai 2018 in Split, in Kroatien, geplant ist.

Die Konferenz wurde von den beiden Hauptorganisatoren eröffnet. Der Ehrenkonsul der Republik Kroatien in Krakau, Paweł Włodarczyk, führte in die Thematik ein und begrüßte die Anwesenden. Dagegen hieß der Prorektor der UPJPII, Prof. Józef Stala, die Gäste in der Stadt Krakau, an der Universität, die den Namen Johannes Pauls II. trägt und in der Bibliothek der UPJPII willkommen, die der Papst selbst im Jahr 2002 eingeweiht hat. Anschließend vollzog Dr. Andrea Bekić, Botschafter der Republik Kroatien in Polen, die feierliche Eröffnung, indem er an die Ereignisse erinnerte, die Kroatien und Johannes Paul II. verbunden haben. Im ersten Referat „Chorwacja jako inspiracja dla Jana Pawła II” (Kroatien als Inspiration für Johannes Paul II.) ging Kardinal St. Dziwisz auf die Beziehungen von Johannes Paul II. zu Kroatien ein. Dabei betonte er besonders, dass der Papst ein Mensch des Gebets, der Arbeit und des erkennbaren Stigmas des Leidens war, so wie auch Kroatien gelitten hat. Deshalb segnete er vom Berg aus das geliebte kroatische Volk. Es folgte der Vortrag von H. H. Prof. Dr. Ivan Bodrozić „Jan Paweł II i historia Chorwackiego narodu" (Johannes Paul II. und die Geschichte des kroatischen Volkes), in dem er darauf einging, wie der polnische Papst die Kroaten in ihren bedeutenden geschichtlichen Momenten unterstützt hat (die Kroaten waren das erste slawische Volk, das vor 1300 Jahren den christlichen Glauben angenommen hat). Dagegen listete der Ehrenkonsul Paweł Włodarczyk in seinem Referat „Czy papież Jan Paweł II mógł być spokrewniony z Chorwatami?” (Könnte Papst Johannes Paul II. mit den Kroaten verwandt sein?) zahlreiche Argumente auf, um die 
aufgestellte These zu untermauern. Der Vortrag von Ivana Cogelja, Vertreterin des Büros der Kroatischen Bischofskonferenz für die Jugend, befasste sich mit dem Thema „Wpływ wizyt Jana Pawła II w Chorwacji na działalność chorwackich organizacji młodzieżowych" (Der Einfluss des Besuchs von Johannes Paul II. in Kroatien auf das Wirken der kroatischen Jugendorganisationen). Darin erinnerte sie unter anderem an die berühmte Begegnung von Johannes Paul II. mit der Jugend Kroatiens in Solin. Damals folgten die jungen Kroaten dem Heiligen Vater und bezeichneten ihn als ,unser Papst”. Es entstanden pastorale Zentren für die Jugend, christliche Verbände, vokale und instrumentale $\mathrm{Mu}$ sikgruppen, eine kleine Liga der Erzdiözese in Split sowie musikalische Treffen. "Wydawnictwa chorwackie związane z nauczaniem Jana Pawła II" (Kroatische Veröffentlichungen im Zusammenhang mit dem Lehrwerk Johannes Pauls II.) lautete der Titel des Referats von Prof. Dr. Bozidar Nagy SI. Er verwies auf vier Gruppen von Publikationen über Johannes Paul II. in kroatischer Sprache: 1. Offizielle Dokumente (Enzykliken, Apostolische Schreiben, Briefe...); 2. Veröffentlichungen mit Karol Wojtyła und Johannes Paul II. als Autor - 24 Bücher; 3. Andere Autoren (aus Kroatien oder dem Ausland über Johannes Paul II. 53 Publikationen; 4. Ansprachen und Grußbotschaften an die Kroaten und über Kroatien über - 500 Seiten. Der Referent präsentierte auch eine CD mit Ansprachen Johannes Pauls II. an die Kroaten. Im Anschluss daran präsentierte Dr. Gina Šparada ihren Vortrag „Jan Paweł II w kulturze chorwackiej - wpływ na młodzież poprzez muzykę: Papa Band" (Johannes Paul II. in der kroatischen Kultur - Einfluss auf die Jugend durch die Musik: Papa Band), bereichert mit Musik und Gesang des Teams der Papa Band, die sich im Jahr 1998 anlässlich der Reise von Papst Johannes Paul II. nach Solin gegründet hatte. Seit damals findet in Solin alljährlich im Gedenken an dieses Ereignis das Festival religiöser Lieder „Papa Fest” statt, wo sich Bands und Sänger aus dem ganzen Land zum gemeinsamen Musizieren versammeln. Das nächste Referat „Zabytki i tablice pamiątkowe w budynkach - dedykowane Janowi Pawłowi II” (Denkmäler und Gedenkinschriften an Gebäuden - gewidmet Johannes Paul II.) übernahm Domagoj Pejić, Redakteur des katholischen Radiosenders in Kroatien. Er führte eine Vielzahl an Beispielen auf - Skulpturen, Kapellen, Kirchen, Promenaden, Küstenabschnitte, Säle, Denkmäler sowie Gedenktafeln, die dem Papst gewidmet sind - und unterstrich damit, dass diese auf Johannes Paul II. als geistlichen Führer verwiesen, als berühmten Menschen, der im Herzen jedes Kroaten sei. Alle diese sichtbaren Zeichen verblieben ein Ausdruck der Dankbarkeit für seine Verteidigung Kroatiens. Es folgte der Vortrag „Sportowe akcenty związane 
z Janem Pawłem II w Chorwacji" (Sportliche Akzente in Kroatien in Verbindung mit Johannes Paul II.) von Stipe Pletikosa, einem bekannten Sportler Kroatiens er war Fußballer in der Nationalmannschaft Kroatiens und spielte bei dem Verein Hajduk Split. Er bezeugte seine Wertschätzung für den Papst, erinnerte aber gleichzeitig auch an die über 120 Begegnungen von Johannes Paul II. mit Sportlern sowie an den Aufruf: „Hajduk pierwszy i Jan Paweł II” (Hajduk der erste und Johannes Paul II.). Im Anschluss daran trugen Prof. Dr. Jadranka Garmaz und Dr. Angelina Gašpar ihr gemeinsames Referat vor: „Postać i ewangelizacja Jana Pawła II w chorwackich mediach elektronicznych" (Gestalt und Evangelisierung Johannes Pauls II. in den elektronischen Medien Kroatiens). Darin bezogen sie sich auf häufig in verschiedenen Printmedien veröffentlichte Untersuchungen, die sich sowohl mit der Person als auch mit dem Lehrwerk des Papstes befassten. Dagegen ging Prof. Elżbieta Osewska in ihrem Vortrag „Wydziały Teologiczne na Chorwacji w służbie nauczania Kościoła ze szczególnym uwzględnieniem myśli Jana Pawła II" (Die Theologischen Fakultäten in Kroatien im Dienst der kirchlichen Lehre unter besonderer Berücksichtigung der Gedanken Johannes Pauls II.) auf ihre Erfahrungen bei der Akkreditierung der Katholischen Theologischen Fakultäten in Kroatien ein. Sie verwies darauf, dass jene Fakultäten dem Evangelium und der Kirche stets treu verbleiben, indem sie kontinuierlich das Lehrwerk Johannes Pauls II. durch die Organisation von Konferenzen sowie durch wissenschaftliche Veröffentlichungen und Diplomarbeiten ihrer Studenten aufgreifen und thematisieren. H. H. Prof. Dr. Josip Mužić beschäftigte sich in seinem Referat "Jan Paweł II i chorwacka maryjna pobożność" (Johannes Paul II. und die kroatische Marienfrömmigkeit) auf die Verbundenheit des Papstes mit der kroatischen Marienverehrung, denn Maria nahm auch im Leben des Heiligen Vaters eine bedeutende Rolle ein. Er verwies insbesondere auf das Rosenkranzgebet, auf Maria als Königin, auf Johannes Paul II., von den Kroaten als „unser Papst” bezeichnet, auf seine große Liebe zu Gott und dem Vaterland. Er betonte natürlich ebenso, dass sich der Papst und die Kroaten gegenseitig in ihrer Liebe zu Maria ergänzten. Den Abschluss bildete der Vortrag „Papież św. Jan Paweł II i Chorwaci w czasach komunizmu (1978-199o)” (Der Papst hl. Johannes Paul II. und Kroatien in den Zeiten des Kommunismus (1978-1990)) von Dr. Miroslav Akmadža. Er ging auf die Beziehung des Papstes zu den Kroaten während der Zeit des Kommunismus ebenso ein wie auf die Dilemmas der Kommunisten vor der Reise von Johannes Paul II. nach Kroatien. Der Referent erinnerte an das Handeln der jugoslawischen Kommunisten, für die eine Einladung des Papstes nach Jugoslawien unumgänglich war, um die 
Glaubwürdigkeit des Staates zu erhalten, gleichzeitig jedoch in politischer und gesellschaftlicher Hinsicht außerordentlich große Sorgen vor Unruhen bereitete. Letztendlich wurde die Visite nicht durchgeführt und Johannes Paul II. musste bis zur Zerschlagung Jugoslawiens und der Unabhängigkeit des kroatischen Staates warten, die dieser erstmalig im Jahr 1994 erlangt hatte.

Nach dem Vortrag der Referate entstand eine lebhafte Diskussion. Abschließend fassten die Hauptorganisatoren und Leiter der Konferenz, H. H. Prorektor J. Stala und der Ehrenkonsul P. Włodarczyk, die Ergebnisse und Einsichten der Konferenz zusammen. Beide endeten mit einem Gedicht.

H. H. J. Stala:

„Polak i Chorwat dwaj przyjaciele, „Der Pole, der Kroate, sind zwei Freunde, razem mogą zdziałać wiele". gemeinsam können sie vieles bewirken".

Darauf eingehend spann P. Włodarczyk den Faden weiter:

„Chorwat, Polak przyjaciele, łączy obu bardzo wiele.

Choć nie mamy wspólnych granic,

To jest przyjaźń między nami.

Bo gdy Polak widzi Chorwata,

To traktuje go jak brata.

Chorwat widząc gościa z Polski, Sieht der Kroate den Gast aus Polen, Ma już z głowy wszystkie troski. sind ihm schnell alle Sorgen aus dem Kopf.

Oba kraje piękne równie, mają morza, mają turnie.

Mają piękne miasta, wioski, jest też miłość, są też troski.

U Chorwata Polki piękne, zawsze miłe i majętne.

A Chorwatki w Polsce słynne, że w miłości są stabilne.

Choć są czasy zawsze trudne, to budujmy dobro wspólne.

By następne pokolenia, Mogły mówić bez wytchnienia: Chorwat, Polak, przyjaciele...."
Der Pole, der Kroate, als Freunde verbindet beide vieles.

Obwohl wir keine gemeinsame Grenzen haben,

gibt es die Freundschaft zwischen uns.

Denn wenn der Pole den Kroaten sieht, behandelt er ihn wie einen Bruder. Beide schönen Länder gleichermaßen haben Meer, haben Bergeshöhn. Haben schöne Städte, Dörfer, es gibt Liebe, doch auch Sorgen. Für den Kroaten sind die Polinnen schön, immer liebevoll und vermögend.

Die Kroatinnen in Polen sind dafür berühmt, dass sie in der Liebe standhaft sind.

Obwohl die Zeiten immer schwierig sind, bauen wir am gemeinsamen Wohlergehen. Damit die nächsten Generationen, weiter unermüdlich sagen können: Der Kroate, der Pole, Freunde sind sie...".

An der Konferenz nahmen ca. hundert Personen teil, ein großer Teil davon waren geladene Gäste aus Kroatien und Polen, u.a. der Vorsitzende der Kroatisch-Polnischen Parlamentsgruppe Dr. Damir Tomić, der Vorsitzende der 
Polnisch-Kroatischen Parlamentsgruppe Tomasz Głogowski, der Vorsitzende der Versammlung der Region Split-Dalmatien Petroslav Sapunar und seine Stellvertreterin Ante Šošić, die Vorsitzenden des konsularischen Korps aus Österreich, Frankreich, Malta, Deutschland und Ungarn. Unmittelbar vor dem Beginn der Konferenz hatte Dr. Andrea Bekić, Botschafter der Republik Kroatien, ebenfalls in der Bibliothek der UPJPII, die Ausstellung „Bądźcie narodem nadziei - wystawa o Janie Pawle II i Chorwacji” (Seid ein Volk der Hoffnung Ausstellung über Johannes Paul II. und Kroatien) eröffnet, die von der Botschaft der Republik Kroatien sowie dem Museum Johannes Paul II. und dem Primas Wyszyński in Warschau organisiert worden war. 